\title{
On the dark side of open access and new expectations of scientific productivity in adult education research
} An analysis of publication activities in "predatory journals"

\author{
Tim Vetter • Michael Schemmann
}

Received: 2 February 2021 / Revised: 31 May 2021 / Accepted: 9 June 2021 / Published online: 21 July 2021

(C) The Author(s) 2021

\begin{abstract}
The aim of this paper is to explore international adult education research in the context of predatory publishing or predatory journals. The paper presents empirical characteristics of predatory journals, determines the quantitative occurrence of predatory journals in the field of adult education by means of a catalogue of criteria, takes a closer look at the authors of adult education contributions identified, and examines the content and quality of the contributions. The article deals with the phenomenon of predatory publishing, an unintended side effect of the Open Access movement, and thus operates in the context of Open Science.
\end{abstract}

Keywords Predatory journals · Predatory publishing · Open Access Journal analysis · International adult education research $\cdot$ Open Science

Tim Vetter, M.A. $(\bowtie) \cdot$ Prof. Dr. Michael Schemmann

Universität zu Köln, Cologne, Germany

E-Mail: t.vetter@uni-koeln.de

Prof. Dr. Michael Schemmann

E-Mail: michael.schemmann@uni-koeln.de 


\section{Die Schattenseite von Open Access und neuen Erwartungen an die wissenschaftliche Produktivität in der Erwachsenenbildungsforschung}

Eine Analyse der Publikationsaktivitäten in „Predatory Journals“

Zusammenfassung Ziel des Beitrags ist die Exploration der internationalen Erwachsenenbildungsforschung im Kontext von Predatory Publishing bzw. Predatoy Journals. In den Ausführungen werden empirisch erarbeitete Kennzeichen von Predatory Journals dargestellt, mittels eines Kriterienkatalogs das quantitative Vorkommen von Predatory Journals im Feld der Erwachsenenbildung bestimmt, die ermittelten Autoren von erwachsenenpädagogischen Beiträgen näher beleuchtet sowie die Inhalte und Qualität der Beiträge untersucht. Der Beitrag nimmt sich mit dem Phänomen des Predatory Publishing einem nicht intendierten Nebeneffekt der OpenAccess-Bewegung an und operiert somit im Kontext von Open Science.

Schlüsselwörter Predatory journals · Predatory publishing · Open Access Zeitschriftenanalyse $\cdot$ Internationale Erwachsenenbildungsforschung $\cdot$ Open Science

\section{Introduction}

The higher education system and its organizations have been subject to profound change in recent decades. This holds true for several realms of the higher education system.

As regards teaching, the so-called Bologna process marks the beginning of the most dramatic changes in European higher education (Becker et al. 2020, p. 1). The process consisting of a series of agreements between European countries was intended to ensure comparability in the standards and quality of higher-education qualifications. However, it also evoked a development of a more competence- and student-centered approach to learning (Gover et al. 2019), which brings about questions of architecture, learning space and access to learning material (e.g. Stang and Becker 2020). This debate is not confined to the European context but is led in higher education systems around the world.

As regards research and publishing the Open Access movement can certainly be seen as one of the major changes. Originating in the United States of America with the establishment of a repository to make preprints in physics freely accessible, it covers the whole academic world by now and has profoundly changed the way research findings are being published and accessed.

Finally, regarding the governance of higher education organizations, massive changes were brought about by the introduction of new instruments subsumed under the heading New Public Management. At this point, output-orientation, quality management, management by objectives on all levels or, increase of competition might suffice as catchwords to circumscribe the changes. Within research on governance of higher education organizations the consequences were addressed in several studies (de Boer et al. 2007; Schimank 2009; Heinze et al. 2011). 
This paper focuses on unintended effects of a combination of two of the abovementioned developments. More concretely, we will look at the combination of the Open Access movement on the one hand and the changes of governance of higher education organizations on the other hand. The combination of both led to an unintended effect which we label as the "dark side", i.e. the emergence of Predatory Journals (PJs) resp. Predatory Publishing (PP). While there is no universally accepted definition of PJs (Cobey et al. 2018, p. 1), many empirical studies on the topic are based on the definition by Jeffrey Beall, who is seen as a pioneer of the academic debate on the publication phenomenon. Thus, PJs are defined as publication organs whose publishers exploit the Gold Road form of Open Access (OA) publishing and the associated form of financing via Article Processing Charges (APCs) for profit by claiming to guarantee legitimate quality control standards, such as a peer review process, but fail to keep this promise and accept all submitted manuscripts without review (e.g. Beall 2013, 2016; Cortegiani et al. 2019).

Although there is a tradition of analyzing scientific publishing in general and the spectrum of scientific journals in particular within adult education research (Rubenson and Elfert 2014), PJs have not yet become the subject of analysis in the field of adult education research. Thus, it is largely unclear how to characterize these journals with adult education relevance. What is more, it is unclear who publishes in these journals on which adult education topics and in which scientific quality.

This paper seeks to address this desideratum by first analyzing the above-mentioned developments as regards the Open Access movement and the governance of higher education organizations in a more detailed way. We will frame this analysis by drawing back on neo-institutionalist theory (Chap. 2).

Following, we will identify criteria for classifying potential PJs based on an integrative literature review of cross-disciplinary empirical work that treats PP as a central object of inquiry. On this basis, potential PJs relevant to adult education research are identified and examined (Chap. 3). Our study is methodologically oriented towards journal analyses and carries on by focusing on quantitative characteristics of the journals or their publishers (4.1), socio-demographic characteristics of the authors (4.2), the topics discussed (4.3), and the formal scientific quality of the texts (4.4). In a final chapter we draw conclusions and give an outlook on further research (Chap. 5).

\section{Theoretical background and context}

The starting point of this paper is the combination of the Open Access movement on the one hand and the changes of governance of higher education organizations on the other hand. Thus, we will take a closer look at both processes which, according to our analysis, brought about PJs as well as PP. We will also draw back on some notions of neo-institutionalist theory as a theoretical framework.

PP operates in the slipstream of the Open Access movement. The idea of free access to scientific literature on the Internet in turn emerged in the course of the journal crisis that developed between the 1970s and 1990s. While scientific journals were disseminated by the respective professional societies by means of the "gift 
exchange" principle until the 1960s (Hofmann and Bergemann 2014), the launch of the Science Citation Index (SCI), which identifies the most relevant journals in the various disciplines by calculating the impact factor (IF), gave rise to the socalled core journals, which were increasingly in demand by students and scientists at university libraries due to their (apparent) relevance (Hofmann and Bergemann 2014; Heise 2018, p. 112). The resulting economic attractiveness eventually ensured that the relevant journals were bought up by large publisher groups. However, this had far-reaching consequences. On the one hand, the market quickly faced stagnation from an economic perspective. While the profit margins and capacities of commercial publishers continued to rise due to their "monopolistic pricing policy" (Brintzinger 2010, p. 333), the budgets of university libraries did not increase but even declined slightly (Frosio and Derclaye 2014, p. 117; Lorenz 2014). On the other hand, control over the dissemination of scientific knowledge was lost with the surrender of exploitation rights (Hofmann and Bergemann 2014).

This economic and systemic crisis situations in scientific publishing and research provided the breeding ground for the OA movement, which formed at the beginning of the 1990s with the emergence of the Internet and went public in 2001 at a conference of the Open Society Institute with the demand for OA to scientific publications for all people (Stempfhuber 2009, p. 116). Over the next three years, a broad group of supporters developed solutions for the neuralgic points of OA.

As regards financing, two options were singled out. On the one hand, there is the possibility of financing publications through institutions. On the other hand, there is the "author-pays model", in which authors pay so-called APCs to the OA publishers for the professional publication of the journals (Björk and Solomon 2012, p. 2). Contrary to the anti-commercial orientation of the OA movement, the "author-pays model" has become a common business model in OA. Although many OA publishers and journals use the instrument of APCs merely to cover their costs, this financing channel provided the entry point for commercial academic publishers into the OA market. OA publication channels and publishers' business models are directly linked. Gold Open Access refers to one of two main publication channels in OA. This is understood as the primary publication of scientific articles in OA journals, or selfpublishing for short (Döbler 2020, p. 19). These newly founded journals are moving away from financing models via subscription or access fees. Instead, the alternative funding models described above apply here. Financing via APCs is a central pillar of funding for these journals (Pieper 2017, p. 1). The recommendation to finance the publication of Gold OA journals via such APCs has gained international acceptance over the past nine years. With the opening towards the market of OA, not only the core journals but also players who were not interested in global and free scholarly communication but merely wanted to exploit the business model associated with the movement for economic motives came onto the scene. Over time, a: "[...] new industry of journals which engage in deceptive and dishonest practices, falsely claim to offer peer review and publish any article in exchange for a fee." (Bagues et al. 2019, p. 462).

In the following, we want to address changes in higher education organizations. Changes in the governance of higher education organizations can be subsumed under the term new public management. However, one analytical concept to cover 
these changes is the so-called governance equalizer developed by Schimank (2007). Drawing on the work of Clarke (2001) Schimank (2007) developed five dimensions by which governance of higher education systems can be distinguished. State regulation can be seen as a first dimension, covering the classical notion of hierarchical authority by the state through regulations and law. Stakeholder guidance is the second dimension and draws on the delegation of power by the state to other actors such as university boards who then give advice and guidance to the organization. Academic self-governance refers to mechanisms of collegial decision-making, whereas managerial self-governance focuses the hierarchies within university leadership and addresses the power of presidents or deans. Finally, as the last dimension, competition for money as well as for prestige is singled out. Performance indicators as well as evaluations are characteristic of this dimension (Schimank 2007; de Boer et al. 2007). Referring to this model, various studies were carried out operationalizing the model with indicators as well as comparing the governance of higher education systems with each other (e.g. Heinze, et al. 2011; de Boer et al. 2007, p. 15). As one central finding, it can be pointed out, that governance of universities has undergone profound change and that "[...] changes are going in the direction of NPM" (de Boer et al. 2007). As such, amongst other trends, it can be observed that the importance of the dimension of competition for money and prestige increases. This particularly refers to third-party funding of research projects as well as to publications in highranked, peer-reviewed journals. What is more, the managerial self-governance also comes into play at this point, since the allocation of money is dependent on performance indicators referring to publication output. It is exactly at this point where the governance of higher education organizations and the Open Access movement are interdependent and reinforce each other.

Finally, we want to add some notions and concepts of neo-institutionalist theory as a theoretical framework. The theoretical approach seems particularly appropriate here, since it takes into account the organizations as well as their environment and environmental expectations. Key concepts of neo-institutionalist theory to be referred to in this context are institutions, legitimacy and mimetic isomorphism.

To start off, DiMaggio and Powell (1991) get to the heart of neo-institutionalism with the following quotation: "The new institutionalism in organization theory and sociology comprises a rejection of rational-actor models, an interest in institutions as independent variables, a turn toward cognitive and cultural explanations and an interest in properties of supraindividual units of analysis that cannot be reduced to aggregations or direct consequences of individuals' attributes or motives" (DiMaggio und Powell 1991, pp. 8). Without any doubt, the term institution is central to the theory. Particularly, institutions which have an impact on social life are of interest. Institutions are understood as regulations, norms, values and beliefs which substantially influence processes in a binding and significant manner (Senge 2006).

The concept of institutions is closely connected to the notion of legitimacy in neo-institutionalist theory. It is assumed that organizations acquire legitimacy by acting conform to environmental expectations. Meyer and Rowan (1977) characterize potential consequences as follows: "But conformity to institutionalized rules often conflicts sharply with efficiency and, conversely, to coordinate and control activity 
in order to promote efficiency undermines an organization's ceremonial conformity and sacrifices its support and legitimacy" (Meyer and Rowan 1977, p. 340 f.).

By taking into account the importance of the environment of the organizations it is also possible to analyze processes of isomorphism. DiMaggio and Powell (1991) distinguish three mechanisms of isomorphism: coercive isomorphism brought about by regulations and law, mimetic isomorphism in the sense of an imitation of organizational elements which are perceived as successful, and normative isomorphism which is driven by e.g. preferences of problem solutions of professions (DiMaggio and Powell 1991).

\section{Methodological design}

The present exploratory study is based on a methodical design consisting of three components.

In a first step we will carry out an integrative literature review, which focuses on cross-disciplinary empirical findings on PJs. At the heart of this review is the question, what criteria empirical research papers use to classify scientific journals as predatory and what methodological approach they use to approach the object of research.

The results obtained from the review serve as a prerequisite for quantitative data analysis since criteria can be derived from the empirical findings on PPs and PJs that can be used to derive statements on the probability of predatory intentions in selected potential PJs.

The third and final step of the research deals with the analysis of adult education papers identified as relevant in PJs as regards authorship, content and quality. The structured analysis of the content-related data on the articles studied is based on the adult education journal analyses of Rubenson and Elfert (2015), Cherrstrom et al. (2017), St. Clair (2011) and Taylor (2001).

\subsection{The integrative review of empirical findings on PJs}

The integrative review (IR) offers the possibility of including both experimental and non-experimental studies without having to compromise on systematicity and intersubjectivity. The IR "[...] also combines data from theoretical and empirical literature, and has a wide range of purposes, such as definition of concepts, review of theories and evidence, and analysis of methodological problems of a particular topic" (Tavares de Souza et al. 2010, pp. 103). Whittemore and Knafl (2005) have designed a five-stage method sequence to ensure systematic implementation of the method. The first phase includes the development of the guiding question of the review. The second phase includes the literature search. In the third phase, the generated data are evaluated with regard to self-determined quality categories. Phase four is the data analysis, which can also vary in terms of its analysis criteria according to the research question and the corresponding needs. Finally, in phase five, the results are presented in a structured way (Whittemore and Knafl 2005, pp. 548-552). The review prepared in the context of this work follows these steps and incorporates 
TITLE ABSTRACT ("Predatory Journal*" OR "Predatory Publish*" OR "write-only publish*" OR
"deceptive publish*" OR "räuberisches Veröffentlichen" OR "Predatory open-access publish*" OR
"dodgy Open Access journal*" OR "illegitimate journal*" OR "deceptive journal*" OR "journal*
operating in bad faith" OR "dark journal*")
AND
TITLE ABSTRACT ("Study" OR "Studie" OR "explorative*" OR "monitoring" OR "Evaluation" OR
"Qualitativ*" OR "Quantitativ*" OR "empirisch" OR "empirical")

Fig. 1 Search term of the IR

individual elements from the phase description of general systematic reviews by Gough et al. (2013).

In order to generate sufficient studies on the young phenomenon of PJs, the guiding questions of the IR are interdisciplinary.

Since deception is a central pillar of the business model for PJs and their publishers, they are characterized by intransparency. This makes it difficult to determine central characteristics for a discipline-independent definition of PJs. Therefore, the first guiding question of this integrative review is: "Which discipline-independent characteristics of PJs and their publishers are taken up or elaborated to define the phenomenon in the context of empirical studies?".

Following this, the second guiding question is "How or according to which criteria do the empirical studies identified as relevant determine scientific OA journals as 'predatory' or 'potentially predatory'?'.

The third and final guiding question refers to the perspectives of the identified studies. The guiding question: "Which methods do the identified empirical studies use to investigate which aspect of predictive publishing or PJs?" is intended to reveal possible research desiderata. Behind the question is the assumption that PJs is a phenomenon with multiple manifestations that may not have been focused on with the same emphasis so far. The question serves as a needs analysis for the third part of this study, which refers to the results of this question in terms of content.

To generate relevant studies from scientific journals, anthologies and monographs, seven literature databases were selected.

Publications with a publication date up to April 2019 were included in the search as well as national and international journal articles, dissertations, monographs, and anthologies written in German or English. On the content level, publications that deal empirically with PJs or PPs as a whole or with selected components of these publication phenomena as the central object of investigation were included. The following Fig. 1 shows which search keywords were used in the databases.

\subsection{The quantitative data analysis of potential PJs}

The quantitative exploration of potential PJs, authors, and their contributions in the field of adult education research is built up under the influence of the generated findings on empirically developed characteristics of potential PJs and the identification of possible databases or other sources for access to potential PJs and their publish- 
ers. Empirical-quantitative exploration is a strategy of object exploration that lends itself to very large quantitative data sets in order to discover previously unnoticed or unrecognized patterns in them and to develop new theories on this basis (Döring and Bortz 2016, p. 173). The aim of the exploration of the field is to generate quantitative statements on the size of the field and to collect localization data from potential PJs and the identified authors, as well as data relating to the academic profiles of the authors. The methodological procedure in this step of the analysis of the study is divided into the selection of data sources, the identification of potential PJs with possible relevance for adult education, the selection of relevant contributions in the extracted OA journals and the subsequent analysis of the potential PJs and the authors of adult education contributions.

Access to potential PJs is problematic. Although the Beall's List (BL) ${ }^{1}$ provides a comprehensive list of potential PJs, publishers and even alternative or misleading metrics, this has no longer been maintained by the originator Beall since 2017. Since 2017, the list has been maintained by anonymous researchers, who, like Beall, have had to deal with a variety of criticisms regarding incorrect entries, the transparency of the journal selection and the associated subjectivity. At the same time, however, there is no alternative to the BL and its offshoots. The North American private sector analytics company, Cabell, does provide an extensive list of potential PJs, but this comes at a huge cost to individuals and is also open to criticism for lack of transparency. This data source is therefore out of the question due to the lack of a licence. For this reason, the BL (Journal-list and Publisher-list) represents a central data source in the present survey.

Since the latter source was updated two years ago, the List of Predatory Journals $(\mathrm{LoPJ})^{2}$, which is maintained by a group of anonymous researchers, is also used. Like the BL, this list separates publishers from OA journals. Both lists are also included here.

As a third source of supply, the paper uses suspicious-looking email invitations from OA journals that were sent to researchers from the Qualitative Sozialforschung (QSF_L) mailing list.

The identified OA journals were reviewed along different categories and subsequently included or excluded. For the two lists of potentially predatory publishers on the BL and the LoPJ, the publishers were checked along the criteria accordingly. These criteria, resulting from the integrative review, can be divided into three groups.

The first of the category groups determines whether the identified journal or publisher is listed in an integral whitelist for scientific OA journals. For this purpose, the four whitelists Open Access Scholarly Publishers Association (OASPA), Scopus, Directory of Open Access Journals (DOAJ) and Web of Science were selected. All publishers and journals were searched in the lists.

The second category group focuses on a central feature of potential PJs and publishers that relates to their location and is disclosed in the context of the evaluation of the review conducted. Thus, this group of scientific publication bodies is characterized by a concealment of their true locations. In order to prove this concealment,

\footnotetext{
1 https://beallslist.net.

2 https://predatoryjournals.com.
} 
a multidimensional model was created, as in the first category group. This includes the location information on the websites of the identified journals and publishers, the localization data of the Internet Protocol (IP) addresses and the International Standard Serial Number (ISSN) as well as the information on the owner of the journal domain in the WHOIS protocol.

The third group of categories takes a look at the contents of the websites of potential PJs. In this context, the contact details, the listed metrics and indices as well as suspicious components of the self-descriptions are considered to be indications of predatory behavior.

Along the three category groups presented, "whitelists", "localization" and "homepage", the filtered potential PJs were reviewed and sorted into one of three lists that differ in the degree of potential predatory intent. For further exploration, only those journals were considered that could be included in the list where the probability of predatory intent was upmost. The journals listed here are not included in any of the four whitelists from the first category group. The site check by four sources under the second category group yielded contradictory results for the journals assigned to this list, making an intention to conceal likely. Within the category group "homepage", all OA journals give a misleading IF and list one of the aforementioned suspicious details in the contact information. The attached conspicuous self-descriptions of the OA journals were an optional decision aid if the assignment of individual journals was uncertain.

The potential PJ generated in this way were then searched for articles that indicated adult educational relevance based on keywords in the title.

The main focus of the field exploration is on quantifiable parameters of authors who publish articles with adult education topics in potential PJs. Accordingly, the following parameters were researched: geographical location(s) of the author(s), academic degree at the time of publication, institutional affiliation of the author(s) (including facultative background in case of university affiliation). The survey of the types of organization of authorship and the in-depth look at authors with a university location makes it possible to determine the extent to which academics use potential PJs to publish articles, or whether the phenomenon of PPs in the context of adult education also has non-university appeal.

\subsection{Operationalization of the formal content and quality analysis of generated publications}

Characteristics relating to the quality and content of contributions from potential PJs have so far only been collected by Oermann et al. (2018), as the evaluation of the IR has shown. In the descriptive part, the authors collect the following characteristics of the identified articles: "publisher, journal name, year, volume, issue, article title, first author's last and first name, country of first author, number of authors, length (in pages), and numbers of references, tables (including appendices), figures, illustrations, and photographs" (Oermann et al. 2018). A large part of these characteristics will be collected in the second part of the analysis of this paper in connection with the identification of authors who publish adult education articles in the potential PJs relevant to educational science. The descriptive recording of the 
length of the contributions and the number of sources listed in the bibliography can be seen as more content-related parameters. For the content-related analysis of adult education contributions from PJs, following the work of Oermann et al. (ibid.), the quantitative length of the individual publications measured in page numbers as well as the number of sources in the respective bibliography are therefore recorded and evaluated. The quantitative recording of figures, tables and photographs, on the other hand, is not considered necessary.

From the qualitative-interpretative categories of Oermann et al. (2018), only the first quality criterion is generally transferable, which defines the inclusion of an abstract as a quality feature of scientific articles in journals.

The logical presentation or organization of scientific articles can also be operationalized through objective criteria. For this purpose, the author's guidelines of renowned scientific journals of adult education research offer indications of minimum standards that can be verified even without interpretative work. In order to check the compliance with basic qualitative standards of the contributions to be examined, the given structure of the $\mathrm{ZfW}$ is assumed as a standard within the framework of the formal quality analysis of adult education publications. This structure is divided into five components, consisting of an introduction in which the research question is clearly defined, a theoretical framework in which the research question is embedded in the context of existing literature, a method section that presents the chosen methodology of the work in a comprehensible way, and the presentation and subsequent discussion of the results. In the case of research reports, it is therefore registered whether this structure is completely adhered to in the correct order. Articles that are not research reports but, e.g., project descriptions, commentaries or otherwise descriptive text forms are not measured against this structure. Here, it is only important that a general structuring of the text becomes clear through chapter titles.

Regarding the bibliographies of the articles examined, this paper, following the Submission Guidelines of the ZfW and the work of Oermann et al. (2018), also takes into account, in addition to the uniformity of the bibliographies, whether all sources cited are actually cited in the continuous text and whether sources are listed that are unpublished and thus not accessible. Furthermore, each bibliography is checked for punctuation and spelling errors as well as for compliance with a systematic order of the sources cited. The analysis also includes whether the bibliography has been formatted and whether Wikipedia appears as a source in the bibliography.

The text type of the articles is also determined by the information provided in the abstract and by recording the structure of the publications. Following Oermann et al. (2018), a differentiation is made between research reports, case studies, project descriptions, literature reviews and descriptive texts.

\section{Findings}

The following presentation of the study findings is divided into four parts. First, the results of the IR are presented with regard to characteristics of PJs. Then, the quantitative findings of the journal analysis in the field of adult education research 
are explained and interpreted individually. This interlocked approach is continued in the subsequent author analysis as well as in the final formative quality analysis of adult education articles in the potential PJs examined.

\subsection{Characteristics of PJs and their publishers - results of the IR}

A total of 353 publications were included in the integrative literature search. By using a multi-stage screening procedure, the corpus of relevant articles was reduced to 58 publications. Fig. 2 .

The analysis of the publication dates shows that PJs and PP have just recently become relevant as a central object of study. Even though the subject has indeed been addressed within the last ten years, $74.14 \%(n=43)$ of the empirical publications identified were published between 2017 and 2019. The results show that there is a clear research focus on the North American continent $(44.83 \%, n=26)$. In Europe, Italy stands out with a total proportion of $12.07 \%(n=7)$. Overall, a global engagement with PJs and PP can be seen through the IR. With regard to the disciplinary positioning of the journals, it becomes clear that especially journals with a medical focus publish empirical studies on topics of PJs and PP (19 out of 49 journals). The second largest group of journals can be found in the subject area of library science, information science and science communication with 13 journals, followed

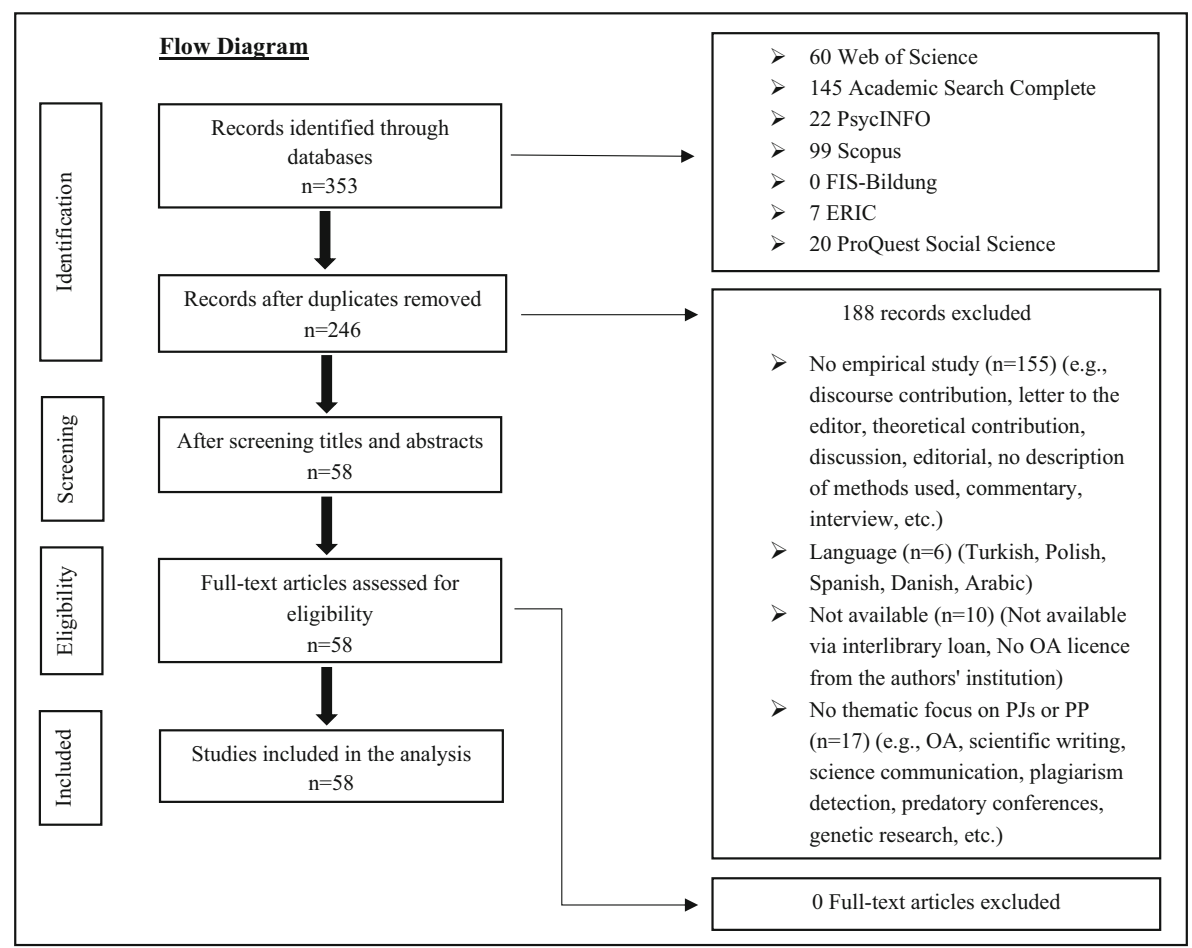

Fig. 2 Flow diagram of the search process within the IR 
by multidisciplinary scientific journals $(n=5)$. No journal can be assigned to the field of educational science.

As regards out central research question for the IR the following characteristics for PP and PJs can be singled out:

1. Potenzial PJs state that they publish in the OA model.

2. They charge APCs to fund predetermined editorial services. The amount of APCs is on average lower than the fees of legitimate academic OA journals. Some potential PJs try to conceal the costs or do not disclose them at all.

3. Potenzial PJs and their publishers come from similar countries across disciplines. These are mostly developing countries and the USA. However, publishers and journals also try to disguise their locations.

4. Essential editorial processes, such as the peer review process, are presented in a non-transparent manner on the websites of the publishers and the journals.

5. The duration of the peer review process is reported to be very short by potential PJs.

6. Potenzial PJs are not usually listed in reputable databases, but this can still happen in individual cases.

7. In order to exude relevance and seriousness, many journals use misleading alternative metrics and impact factors that can be characterized by non-reproducible methods and criteria.

8. The research institutions of authors publishing in potential PJs are often located in similar countries and have similar profiles.

9. Potenzial PJs use an aggressive email marketing strategy to encourage new authors to submit manuscripts.

10. Publications from potential PJs are usually characterized by low quality and low citation counts.

Regarding typical conspicuous features in the editorial board of potential PJs, the review conducted yielded contradictory results, which is why this aspect has not been included in the list.

The second guiding question of the IR relates to the way in which the empirical studies examined identify potential PJs. Overall, the results reveal a dilemma situation regarding the generation of reliable data sources for the scientific investigation of potential PJs. The BL currently represents the only freely accessible compilation of such OA journals and publishers. However, there are some problems with using this list. For one, the original website created by Beall has not been updated since 2017. Although there are offshoots of the list, they are anonymous and therefore not transparent. Secondly, the list is criticized for lacking transparency and objectivity (Teixeira da Silva 2017; Olivarez et al. 2018; Berger and Cirasella 2015). The points of criticism reveal that it is difficult to distinguish between fraudulent OA journals and OA journals that need to be improved in quality due to the lack of standardized criteria. For the explorative analysis of the present work, too, it is therefore important to bear in mind not to use the BL without cross-checking. There are various possibilities for this, which differ in terms of their reliability and the degree of work involved. Even if email invitations from journals or publishers are used as the primary data basis, cross-checking the results is essential to increase the degree 
of objectivity. Despite cross-checking, it is still necessary to speak of potential PJs, as even important verification tools, such as whitelists for OA journals, can contain erroneous entries.

\subsection{Potenzial PJs with relevance for adult education research}

By filtering the three selected sources of potential PJs for relevance to educational science, a total of 96 OA journals could be identified whose titles indicate an educational science focus. ${ }^{3}$ The BL, which has not been updated since 2017 , accounts for a total of $22.92 \%$ of the 96 total results. The LoPJ, which is maintained by anonymous researchers and regularly updated to this day, operates with Beall's extensive catalogue of criteria for assessing predatory intent. With $59.38 \%$, the LoPJ represents the largest share of possible relevant OA journals. Its share of OA journals with a high likelihood of predatory action is also the highest in real terms for all three sources, with 38 potential PJs. The third source for potential PJs is the suspicious call for papers submitted by members of the QSF_L. Although the least results were received via this route compared to the other two sources with a total of 17 potential educational OA journals, 16 of them fulfilled the inclusion criteria of the present study. In addition, each of the potential PJs is retrievable. This underlines the relevance of the non-personalized email invitations from potential PJs as a source for this genre of OA journals.

The 96 results from the three sources include a total of 54,043 contributions from 2937 issues of these papers, 217 publications can be assigned to adult education in terms of content according to the criteria explained. The proportion of adult education publications in the potential PJs reviewed is $0.46 \%$ or 181 contributions.

By applying the evaluation procedure designed from the integrative review to assess potential predatory intentions of OA journals, the number of journals to be analysed in depth was reduced to 63. In the following, therefore, only this group of PJs with high potentiality for predatory intentions will be discussed.

Only two potential PJs from the sample directly address adult education research, both in their titles and in their formulated disciplinary orientation. These are the Journal of Human Resources and Adult Learning and the International Journal of Vocational Education and Training Research, which focuses on vocational education and training as a special sub-area of adult education.

Through the data collected in relation to the volumes of potential PJs relevant to educational science, the founding years of the journals become identifiable and thus also the temporal beginning of educational science and adult education focus of possibly predatory OA journals. The oldest journal, the Journal of Human Resources and Adult Learning, which explicitly refers to adult education, published its first issue in 2005. However, most journals were initially published in $2015(n=13)$. Considering the overall course of journal foundations, an increase in potential PJs with an educational science orientation can be observed from 2010 to 2015. Since 2016, start-ups in this segment have been declining. Only one journal meeting the

\footnotetext{
3 A list of all identified potential PJs with relevance to adult education research is available upon notification to the authors' correspondence addresses provided.
} 
criteria for potential predatory action was published for the first time in 2018. Six journals in the relevant group have not published an issue for at least a year at the end date of data collection (31.01.2019).

In general, it can be assumed that all analyzed journals use the financing model via APCs. Although 11 of the 63 analyzed journals do not provide any information on APCs on their homepages, this should rather be seen as a sign of an attempt at concealment, especially since OA journals that do not charge author fees usually communicate this clearly, such as the OA journals International Journal of Research in Education and Science, the International Journal of Technology, Education, and Resource Management, the Journal of Global Education and Research and the Advances in Social Sciences Research Journal, which were also analyzed in the context of the present study. In connection with the funding of the journals, the various APC models are also striking. For example, 14 of the 63 relevant OA journals charge an author fee specifically for Indian authors in addition to APCs for international authors. These separate fees are quoted in Indian Rupee (RS) currency and are lower compared to the APCs for international authors, which are quoted in USD. Four journals also offer reduced fees for students or registered reviewers. One journal again differentiates in terms of the text type of submission as to how high the APCs are. Five potential PJs charge either a two- or three-tier cost model, which makes the economic situation of the country of the submitting authors the yardstick for the amount of the author fee to be paid. These OA journals distinguish between fees for authors from "low-income countries" or "developing countries", "middleincome countries" and "high-income countries". It is therefore difficult to state an average level of APCs, especially since the values here also vary similarly to the number of published articles. The APCs given in RS converted into USD range from 9.84 USD to 15.60 USD. A German scientist would have to pay an average of 321.92 USD APCs for the selected potential PJs. An Indian author would have to pay 57.12 USD, assuming the person is limited to journals that offer a separate fee for Indian authors.

The analysis of the APCs of potential PJs with relevance to adult education confirms the findings of the integrative review on the financing model. Here, the APCs are on average even significantly lower than the prices of legitimate adult education research journals.

The locations of the potential PJs or their publishers vary greatly. First of all, looking at the locations indicated by the potential PJs themselves, it is noticeable that most journals indicate India as a location $(n=19,30 \%)$. When comparing the 14 journals identified that collect special APCs for Indian authors with the journals that list India as their own location, there is a match of $64.29 \%(n=9)$. At least for these journals, the determination of the real location seems possible via this comparison. The remaining journals with specifically Indian APCs do not provide their own location information. Thus, they belong to the second largest group of the analyzed OA journals $(n=17.27 \%)$. The journals' own information, together with the registration data entered in the WHOIS $\log$, where $27 \%$ of the information was also encoded, are those of the four selected location identification sources with the most unlocatable results. Thus, the location data from the ISSN International Centre register yields only five error messages. On the one hand, these come about because 
potential PJs examined give an ISSN which, according to the register, belong to other journals $(n=3)$, or give unregistered standard numbers for serialized collected works on their homepages $(n=2)$. When the IP addresses were queried, there were only two error messages. However, this does not mean that the IP address query is automatically the most reliable method for determining the real locations. The IP address query only identifies the locations of the providers of the queried homepages of the potential PJs. The providers were also recorded as part of the query of the IP addresses. Assuming that the IP localization data could be equated with the location of the journal providers, nine $(13 \%)$ of the relevant potential PJs would be located in Germany. This seems unlikely given the information generated by checking the ISSN, WHOIS and self-disclosure data, as Germany does not appear in the other sources. However, two firm conclusions about the real locations of relevant potential PJs can be drawn from the results. Firstly, India plays a decisive role in all three sources. In the case of self-disclosures, ISSN country information and domain registrants, India is most frequently identified as a location. India is followed by the USA in three of the four sources, whereby it should be significantly emphasized that no registrant of the journals examined is registered in the USA according to information from the WHOIS protocol. At the same time, this source of information is also characterized by many coded details $(n=16 ; 25 \%)$. Secondly, it is noticeable in the WHOIS and ISSN data that the proportion of identified countries defined as developing countries by the Development Committee of the Organization for Economic Co-operation and Development (OECD) is significantly high. While the proportion in the self-declarations, excluding journals that do not list a location, is only $10.87 \%(n=5)$ and the provider locations can also be attributed to developing countries at a low rate of $16.31 \%(n=10), 51.79 \%(n=29)$ of the identified OA journals are located in developing countries as measured by the ISSN data and even $73.33 \%(n=33)$ with regard to the WHOIS registrant information.

\subsection{Analysis of authorship of adult education articles in potential PJs}

In total, 328 authors from 36 nations are involved in the 181 identified articles. The highest number of articles identified in the potential PJs studied were from Nigeria $(n=39)$, followed by the USA $(n=27)$, Taiwan $(n=20)$, India $(n=19)$ and Malaysia $(n=11)$. The author of one article could not be assigned to a country. 20 of the 36 nations can be described as developing countries according to the OECD criteria already explained (cf. Federal Ministry for Economic Cooperation and Development ibid.). In terms of the number of contributions, 100 of the $181(55.25 \%)$ come from developing countries.

With $87.71 \%$, the majority of the authors can be assigned to a university, followed by colleges $(14.36 \% ; n=48)$. Focusing on the large group of authors working at universities at the time of publication, 74 (27.61\%) researchers work at faculties of education. $26.49 \%(n=71)$ are employed at faculties and departments of adult education.

Regarding the academic titles of the researchers, 59.15\% $(n=194)$ of the authors hold a doctorate. $46.91 \%(n=91)$ of these hold the academic rank of professor. $7.32 \%(n=24)$ are listed as PhD students. People with a Master degree $(12.19 \%$; 
$n=40)$ or a Bachelor's degree $(1.52 \% ; n=5)$ tend to play a minor role. For $26.83 \%$ $(n=88)$ of the authors, no academic titles are given and are also not researchable.

According to the results of the integrative review, the locations of potential PJs are congruent with the locations of the research organizations publishing authors there. Most researchers are located in the USA, India and other developing countries. This is also the case when looking at the authors of articles from adult education research in the potential PJs studied. However, most researchers in Nigeria publish articles on adult and continuing education. What is particularly noticeable about the authors from Nigeria is their distinct adult education background, which emerges from the evaluation of the facultative affiliation. According to this, the 61 academics of the total of 39 contributions from Nigeria are employed at faculties for adult and continuing education at 20 different Nigerian universities. This density of academic representation of adult education research can be explained by the fact that adult education in Nigeria includes young people from the age of 14 (Federal Republic of Nigeria 2004, p. 25). Moreover, the average age in Nigeria is 18.4 years (Statista 2021), and the literacy rate of persons aged 14 and above is just 59.6\% (CIA 2016, p. 548). Adult education in Nigeria therefore has an enormous importance for society as a whole, which cannot be compared to developed countries. The reason why Nigerian scientists publish most frequently in PJs with relevance to adult education can in turn be explained by the system of science funding in the country. Scientists in Nigeria receive additional payment for scientific publications. The quality of the journals is irrelevant (Adomi and Mordi 2003, p. 260; Demir 2018, p. 1298).

The high representation of authors from developing countries should not obscure the fact that researchers from countries with a highly developed research infrastructure, such as the USA or Germany, have also published contributions to adult education research in potential PJs. Nor have they by any means been exclusively inexperienced academics. The majority of those identified hold a doctorate or even a professorial title. This again does not suggest that most of the authors have allowed themselves to be deceived by the appearance of potential PJs but that they also may have opted for deliberate publication in the OA journals studied.

This finding supports the neo-institutionalist-influenced thesis that potential PJs with adult educational relevance secure their continued existence not only through the mimetic imitation and thus deception of academics, but also receive legitimacy from parts of their organizational environment. The imitation of components of reputable adult education journals in terms of using misleading metrics and indices, pretending international relevance, and possibly falsely claiming peer review also serves the scholars who consciously choose to publish in such organs. For example, the case study by Pyne (2017) showed that publications in potential PJs have a positive effect on the reputation of scientists from outside the field and on financial aspects (Pyne 2017, p. 137). With the help of the theoretical framework, it thus becomes clear that potential PJs do not exclusively pose a threat to academic publishing, but also meet a need of the system itself. 


\subsection{Results of the formal content and quality analysis of identified articles in potential PJs}

The analysis of the topics covered by the articles from the field of adult education research identified in the potential PJs fans out along 11 categories. While $20.44 \%$ focus on adult learning from a practical and theoretical perspective, $18.78 \%(n=34)$ of the articles focus on teaching. The articles in these two categories largely address the micro-level of adult education (teaching-learning interaction level). The third largest group are articles that focus on corporate education in the context of Human Resource Management $(17.13 \%, n=31)$. Considering the papers by authors from developing countries identified in Chap. 4.3, it is also noticeable that $26.5 \%$ $(n=26.5)$ of these papers deal with topics that centrally or marginally address typical problems of developing countries, such as poverty reduction, mass unemployment or democracy development. $98.15 \%$ of the total of 27 contributions dealing with these topics were written by authors from developing countries.

The text types are largely divided between research reports $(45.86 \%, n=83)$ and descriptive texts $(39.78 \%, n=72)$, which can also be described as discourse contributions. $75.00 \%(n=54)$ of the research reports use questionnaires to obtain data, $12.50 \%(n=9)$ obtain their data through interviews. Three studies use different methods for data collection.

With reference to the descriptive-formal characteristics of the articles, the average page length excluding the bibliographies is 7.3 pages. The longest article is 27 pages, the shortest articles are two pages long. The articles cite an average of 24.3 sources in the bibliography. The extreme values here are 107 references and articles that cite only two sources. The two articles with only two sources were written by the same author and are not cited in the body text. The articles were published in the period 2006 to 2018. From 2011 (four contributions), the number of adult pedagogical submissions in the potential PJs studied increases steadily, apart from a small dip in 2014, until 2017 (29 articles). In 2018 (20 articles), the number of publications again decreases slightly.

In the context of the quality of the papers, the first thing to look at is the abstracts. This is present in 181 articles. One abstract stood out due to its extreme brevity of only one sentence. Furthermore, the adherence to a common structure for scientific publications in adult education research journals was examined. With the exception of the 58 publications that do not comply with the common structure only because of their text type (descriptive), since they do not cite methodological appendices, $38.21 \%(n=57)$ of the articles show structural deficiencies. For example, $11.38 \%$ $(n=14)$ of the articles lack a theoretical framework, 6.5\% $(n=8)$ have no methods section and $8.13 \%(n=10)$ of the articles have no recognizable chapter structure. $43.90 \%(n=54)$ have no quality deficiencies at all with regard to structure. In $17.89 \%$ $(n=22)$ all structural components of a scientific adult education journal article were present, but in these articles certain components were integrated into others and not clearly separated from each other in the form of chapters.

Another quality criterion is based on the clear formulation of a research question or textual intention. Here it can be seen that $64.64 \%(n=117)$ explicitly formulate a research question/textual intention within the framework of the abstract or 
the methods section. Conversely, this is not the case for $35.36 \%(n=64)$ of the 181 articles.

The final quality control is done by checking the bibliographies. $31.49 \%(n=57)$ of the examined adult education articles have a bibliography with a consistent format. $68.51 \%(n=124)$ do not have a consistent bibliography. It can be seen that $43.86 \%$ $(n=25)$ of these bibliographies do not contain any other deficiencies. The remaining lists $(56.14 \%, n=32)$ most often have punctuation errors $(n=17)$, list sources that are not cited in the running text $(n=11)$ and/or are not formatted $(n=8)$. Bibliographies with an inconsistent format also often have other deficiencies. Only $17.4 \%(n=22)$ of these lists are error-free, apart from the inconsistent style. The most frequent sources of error are punctuation errors in 67 indexes, 35 articles list sources that are not cited in the running text and in 34 publications the bibliography is not formatted. According to the review of this quality indicator, $13.81 \%(n=22)$ of the 181 articles are flawless with regard to the bibliography.

Taking into account the criteria explained in Chap. 3.3, with regard to the four quality-related indicators, $8.29 \%(n=15)$ of the 181 adult education articles are free of deficiencies from a formal quality perspective, $24.31 \%(n=44)$ show only slight deficiencies. Most articles, 32.04\% $(n=58)$, do not meet two of the four relevant formal quality indicators. $35.36 \%(n=64)$ are rated as severely and severely deficient in formal quality.

Thematically, hardly any significant noticeable features can be found in view of the categories. Rather, it becomes clear in the overview of the titles of adult education articles that it is rather the target groups and frames of the examined articles that seem to be of interest. The categories chosen in the course of the thematic evaluation do not reflect the fact that authors from developing countries often deal with typical topics of this national group. In summary, the impression is of a microcosm of adult education publishing by scholars from developing countries who cover topics that are virulent for developing countries emerges. The quality of the peer review of the journals must be viewed critically in light of the examination of the bibliographies and the adherence to a common chapter structure. In view of the many obvious punctuation and spelling errors, it is doubtful whether a review of the manuscript took place at all. The low APCs of potential PJs with relevance to adult education do not seem to ensure sufficient editorial performance.

\section{Conclusions}

The illumination of the selected dark side of Open Access publishing shows that predatory academic OA journals play a quantitatively marginal role in the field of international adult education research. The focused analysis of the identified contributions, the publishing potential PJs and the authors, however, reveals significant patterns that induce follow-up questions for globally networked and mutually participatory adult education research.

Through the neo-institutionalist perspective, it becomes clear that potential PJs with adult educational relevance do not exclusively deceive inexperienced scholars through the mimetic imitation of legitimate OA journals, but also seem to meet a need 
for low-threshold publication venues. Especially for scholars of adult and continuing education research in countries with a weakly developed system of public science funding and simultaneously high competition from other members of the scientific community on the publication market, such as in India, PJs also offer some relief. The analysis of the authors and locations of the journals makes it clear that this target group is relevant in the context of adult education research. The low average number of annual publications in the journals studied does not indicate, at least from a Eurocentric perspective, that the intention of the publishers is mainly profitoriented. The low APCs, which are even lowered again in many potential PJs with relevance to adult education for researchers from developing countries, would mean that the journals would have to increase their publication volume significantly and shorten the frequency of their issues.

Especially the contributions by authors from developing countries deal with issues that are probably underrepresented in Western-dominated journals of adult and continuing education due to the lack of practice framing. Due to the lack of indexing, the visibility of publications in potential PJs has to be rated as poor. Adult education topics that are virulent for developing countries are therefore at risk of not being considered adequately. Publishing adult education researchers from countries such as Nigeria or India need to be specifically addressed through international funding programs and encouraged to submit manuscripts to legitimate OA journals in adult and continuing education. This refers not only to changed marketing strategies, but also to investments in academic literacy. According to Nwagwu (2015), this is essential in order to develop a more critical publishing culture in developing countries (Nwagwu 2015, pp. 119). It is necessary to further investigate how topics and authors from developing countries are represented in existing indexed OA journals in adult and continuing education. It can be assumed that this will be followed by tasks of practice transfer to do justice to the claim of globally networked and mutually participatory adult education.

The question of why many academics from nations with highly developed research infrastructures are to be found among the identified authors also needs to be examined more closely. The cross-disciplinary survey by Kurt (2018), who sees the inexperience of young academics as the main reason for their publishing in potential PJs, does not seem to apply in adult education research, as the vast majority of researchers have sufficient experience in academic publishing in terms of their academic rank or title. Here, mixed-method approaches are appropriate for further inquiry.

Funding Open Access funding enabled and organized by Projekt DEAL.

Open Access This article is licensed under a Creative Commons Attribution 4.0 International License, which permits use, sharing, adaptation, distribution and reproduction in any medium or format, as long as you give appropriate credit to the original author(s) and the source, provide a link to the Creative Commons licence, and indicate if changes were made. The images or other third party material in this article are included in the article's Creative Commons licence, unless indicated otherwise in a credit line to the material. If material is not included in the article's Creative Commons licence and your intended use is not permitted by statutory regulation or exceeds the permitted use, you will need to obtain permission directly from the copyright holder. To view a copy of this licence, visit http://creativecommons.org/licenses/by/4. $0 \%$ 


\section{References}

Adomi, E.E., \& Mordi, C. (2003). Publication in foreign journals and promotion of academics in Nigeria. Learned Publishing, 16(4), 259-263. https://doi.org/10.1087/095315103322421991.

Bagues, M., Sylos-Labini, M., \& Zinovyeva, N. (2019). A walk on the wild side. 'Predatory' journals and information asymmetries in scientific evaluations. Research Policy. https://doi.org/10.1016/j.respol. 2018.04.013.

Beall, J. (2013). Dangerous predatory publishers threaten medical research. Korean Med. Sci, 31(10), 1511-1513. https://doi.org/10.3346/jkms.2016.31.10.1511.

Beall, J. (2016). The open-access movement is not really about open access. TripleC, 11(2), 589-597. https://doi.org/10.31269/triplec.v11i2.525.

Becker, A., Dutz, S., \& Stang, R. (2020). Einleitung. In A. Becker \& R. Stang (Eds.), Zukunft Lernwelt Hochschule. Perspektiven und Optionen für eine Neuausrichtung (pp. 1-11). Berlin: De Gruyter Saur. https://doi.org/10.1515/9783110653663.

Berger, M., \& Cirasella, J. (2015). Beyond Beall's List. Better understanding predatory publishers. College \& Research Libraries News, 76(3), 132-135.

Björk, B.-C., \& Solomon, D. (2012). Open Access versus subscription journals. A comparison of scientific impact. BMC Medicine. https://doi.org/10.1186/1741-7015-10-73.

de Boer, H., Enders, J., \& Schimank, U. (2007). On the way towards new public management? The governance of university systems in england, the Netherlands, Austria, and Germany. In D. Jansen (Ed.), New forms of governance in research organizations (pp. 137-152). Dordrecht: Springer.

Brintzinger, K.-R. (2010). Piraterie oder Allmende der Wissenschaften? Zum Streit um Open Access und der Rolle von Wissenschaft, Bibliotheken und Markt bei der Verbreitung von Forschungsergebnissen. Leviathan, 38(3), 331-346. https://doi.org/10.1007/s11578-010-0095-5.

Cherrstrom, C. A., Robbins, S.E., \& Bixby, J. (2017). 10 years of adult learning. Content analysis of an academic journal. Adult Learning. https://doi.org/10.1177/1045159516664320.

CIA (2016). The world Factbook 2016-2017. The Indispencable source for basic intelligence. Washington: US Government Printing Office.

Clarke, B. (2001). The entrepreneurial university. New foundations for collegiality, autonomy and acievement. Journal of the Programme on Institutional Management in Higher Education, 13(2), 9-24.

Cobey, K.D., Lalu, M., Skidmore, B., Ahmadzai, N., Grudniewicz, A., \& Moher, D. (2018). What is a predatory journal? A scoping review. F1000Research. https://doi.org/10.12688/f1000research.15256. 2.

Cortegiani, A., et al. (2019). Predatory open-access publishing in anesthesiology. Anesthesia and Analgesia, 128(1), 182-187. https://doi.org/10.1213/ANE.0000000000003803.

Demir, S. B. (2018). Predatory journals. Who publishes in them and why? Journal of Informetrics, 12(4), 1296-1311. https://doi.org/10.1016/j.joi.2018.10.008.

DiMaggio, P. J., \& Powell, W.W. (1991). Introduction. In W. W. Powell \& P. J. DiMaggio (Eds.), The new institutionalism in organizational analysis (pp. 1-40). Chicago, London: University of Chicago Press.

Döbler, T. (2020). Wissensmanagement. Open access, social networks, E-collaboration. In W. Schweiger \& K. Beck (Eds.), Handbuch Online-Kommunikation (pp. 1-30). Wiesbaden: Springer VS. https:// doi.org/10.1007/978-3-658-18017-1_17-1.

Döring, N., \& Bortz, J. (2016). Forschungsstand und theoretischer Hintergrund. In N. Döring \& J. Bortz (Eds.), Forschungsmethoden und Evaluation in den Sozial- und Humanwissenschaften (5th edn., pp. 157-179). Wiesbaden: Springer VS. https://doi.org/10.1007/978-3-642-41089-5_6.

Federal Republic of Nigeria (2004). National policy on education. Yaba: NERDC Press.

Frosio, G., \& Derclaye, E. (2014). Open access publishing: a literature review. CREATe working paper. https://doi.org/10.2139/ssrn.2697412.

Gough, D., Oliver, S., \& Thomas, J. (2013). Learning from research. Systematic reviews for informing policy decisions. Alliance for Useful Evidence. https://www.alliance4usefulevidence.org/assets/ Alliance-final-report-08141.pdf. Accessed 29 Jan 2021.

Gover, A., Loukkola, T., \& Peterbauer, H. (2019). Student-centred learning. Approaches to quality assurance. Brüssel, Genf: European University Association.

Heinze, R. G., Bogumil, J., \& Gerber, S. (2011). Vom Selbstverwaltungsmodell zum Managementmodell? Zur Empirie neuer Governance-Strukturen im deutschen Hochschulsystem. In J. Schmid, K. Amos, J. Schrader \& A. Thiel (Eds.), Welten der Bildung? Vergleichende Analysen von Bildungspolitik und Bildungssystemen (pp. 121-147). Baden-Baden: Nomos.

Heise, C. (2018). Von Open Access zu Open Science. Zum Wandel digitaler Kulturen der wissenschaftlichen Kommunikation. Lüneburg: Meson Press. https://doi.org/10.14619/1303. 
Hofmann, J., \& Bergemann, B. (2014). Open Access: Auf dem Weg zur politischen Erfolgsgeschichte? - Teil I: OA im Gegenwind des wissenschaftlichen Zeitschriftenmarkts, Netzpolitik.org. https:// netzpolitik.org/2014/open-access-auf-dem-weg-zur-politischen-erfolgsgeschichte-teil-i-oa-imgegenwind-des-wissenschaftlichen-zeitschriftenmarkts/. Accessed 29 Jan 2021.

Kurt, S. (2018). Why do authors publish in predatory journals? Learned Publishing. https://doi.org/10. 1002/leap.1150.

Lorenz, L. M. (2014). Forschungsinfrastrukturen in der Erwachsenenbildung unter der besonderen Berücksichtigung von Open Access. Bonn: Deutsches Institut für Erwachsenenbildung. http://www.diebonn.de/doks/2013-forschungsmethode-01.pdf. Accessed 29 Jan 2021.

Meyer, J. W., \& Rowan, B. (1977). Institutionalized organizations: formal structure as myth and ceremony. American Journal of Sociology, 83(2), 340-363.

Nwagwu, W.E. (2015). Counterpoints about predatory open access and knowledge publishing in Africa. Learned Publishing, 28(2), 114-122. https://doi.org/10.1087/20150205.

Oermann, M.H., Nicoll, L.H., Chinn, P.L., Ashton, K. S., Conklin, J.L., Edie, A.H., Amarasekara, S., \& Williams, B.L. (2018). Quality of articles published in predatory nursing journals. Nursing Outlook. https://doi.org/10.1016/j.outlook.2017.05.005.

Olivarez, J. D., Bales, S., Sare, L., \& vanDuinkerken, W. (2018). Format aside. Applying Beall's criteria to assess the predatory nature of both OA and non-OA library and information science journals. College \& Research Libraries, 79(1), 52-67. https://doi.org/10.5860/crl.79.1.52.

Pieper, D. (2017). Open-Access-Publikationsgebühren. In K. Söllner \& B. Mittermaier (Eds.), Praxishandbuch Open Access (pp. 77-86). Berlin: De Gruyter. https://doi.org/10.1515/9783110494068.

Pyne, D. (2017). The rewards of predatory publications at a small business school. Journal of Scholarly Publishing, 48(3), 137-160. https://doi.org/10.3138/jsp.48.3.137.

Rubenson, K., \& Elfert, M. (2014). Changing configurations of adult education research: exploring a fragmented map. In B. Käpplinger \& S. Robak (Eds.), Changing configurations in adult education in transitional times (pp. 25-38). Frankfurt a.M.: Peter Lang.

Rubenson, K., \& Elfert, M. (2015). Adult education research. Exploring an increasingly fragmented map. European journal for Research on the Education and Learning of Adults, 6(2), 125-138. https://doi. org/10.3384/rela.2000-7426.rela9066.

Schimank, U. (2007). Governance-Perspektive. Analytisches Potential und anstehende Fragen. In H. Altrichter, T. Brüsemeister \& J. Wissinger (Eds.), Educational Governance. Handlungskoordination und Steuerung im Bildungssystem (pp. 231-260). Wiesbaden: Springer VS.

Schimank, U. (2009). Governance-Reformen nationaler Hochschulsysteme. In J. Bogumil \& R. G. Heinze (eds.), Neue Steuerung von Hochschulen. Eine Zwischenbilanz (pp. 124-139). Berlin: Ed. Sigma. https://doi.org/10.5771/9783845269757.

Senge, K. (2006). Zum Begriff der Institution im Neo-Institutionalismus. In K. Senge \& K.-U. Hellmann (Eds.), Einführung in den Neo-Institutionalismus (pp. 35-47). Wiesbaden: Springer VS.

St. Clair, R. (2011). Writing ourselves into being: a review of the Canadian journal for the study of adult education/la revue Canadianne pour l'Étude de l'Éducation des adultes. The Canadian Journal for the Study of Adult Education, 23(2), 27-44.

Stang, R., \& Becker, A. (Eds.). (2020). Zukunft Lernwelt Hochschule. Perspektiven und Optionen für eine Neuausrichtung. Berlin, Boston: De Gruyter.

Statista (2021). Nigeria: Durchschnittsalter der Bevölkerung von 1950 bis 2020 und Prognosen bis 2050. https://de.statista.com/statistik/daten/studie/1096576/umfrage/durchschnittsalter-der-bevoelkerungin-nigeria/. Accessed 29 Jan 2021.

Stempfhuber, M. (2009). Die Rolle von „open access“ im Rahmen des wissenschaftlichen Publizierens. Diskussionspapiere der Alexander von Humboldt-Stiftung, 12(1), 116-131.

Tavares de Souza, M., Dias da Silva, M., \& de Carvalho, R. (2010). Integrative review: what is it? How to do it? Einstein (São Paulo), 8(1), 102-106. https://doi.org/10.1590/S1679-45082010RW1134.

Taylor, E. W. (2001). Adult education quarterly from 1989 to 1999: a content analysis of all submissions. Adult Education Quarterly, 51(5), 322-340.

Teixeira da Silva, J. A. (2017). Jeffrey Beall's "predatory" lists must not be used. They are biased, flawed, opaque and inaccurate. Bibliothecae.it. https://doi.org/10.6092/issn.2283-9364/7044.

Whittemore, R., \& Knafl, K. (2005). The integrative review. Updated methodology. Journal of Advanced Nursing, 52(5), 546-553. https://doi.org/10.1111/j.1365-2648.2005.03621.x.

Publisher's Note Springer Nature remains neutral with regard to jurisdictional claims in published maps and institutional affiliations. 